Final pre-publication text, please cite published version available at:

https:// mmw.sciencedirect.com/ science/article/abs/pii/S0388000117303765

Authors: Andrés Saenz de Sicilia and Sandro Brito Rojas

Title: Production=Signification: Towards a Semiotic Materialism

Journal: Language Sciences vol. 70 November 2018, special issue on 'Karl Marx and the Language Sciences: Critical Encounters', pp. 131-142

\title{
Production=Signification: Towards a Semiotic Materialism
}

For a being whose fundamental condition is freedom, that produces and consumes objects whose forms are in question, to do so necessarily implies the production and consumption of significations. It is the "political" character of the human animal that makes it, immediately, a "semiotic" being.

(Echeverría, 2010, p.74)

\section{Introduction}

This article offers a reading of Karl Marx's work as a critical theory of forms of social reproduction, in their diversity and plasticity, and to which a communicative dimension is central. Marx's materialist social theory is often taken to relegate language, like consciousness, religion, etc., to a secondary status in his account of the core determining and differentiating bases of human social forms. We aim to challenge this by outlining and developing Bolívar Echeverría's ${ }^{1}$ striking proposition that production and signification have an 'essential identity', taking it as the basis for a Marxist semiotic materialism in which material production always also involves semiotic communication.

Such a proposition, whilst distinctive in its absolute identification of the communicative and practical dimensions of social life, nonetheless remains grounded in central concepts developed by Marx (practice, labour, production, reproduction) identifying a semiotic dimension immanently present - if implicit - in their articulation. As Echeverría shows, if a Marxist 'communicational philosophy' could be said to exist, it would not be the result of the application or extension of a 'core' Marxist theory to the specific domain of language, but the recognition of a semiotic dimension already present within that core. We thus situate this reading within a marginal tradition of Marxist thinkers, from Voloshinov to Della Volpe, Lefevbre and Rossi-Landi, who have recognised 'the inscription of language in the basic pattern of historical Materialism' (Haug, 1996, p.6).

In section 2 we outline Marx's dynamic account of social practices in their diverse historical forms of totalisation - as modes of social (re)production, as well as the metastases of these modes.

${ }^{1}$ On Bolivar Echeverría's life and theoretical work see Saenz De Sicilia and Brito Rojas, 2014; Saenz De Sicilia, forthcoming 2018. 
Marx foregrounds the specificity of human behaviour, in distinction from all other animals, by its sublation of purely 'natural' determinations, opening the possibility of analysing the different historical 'forms of life' in which human existence can be configured. In Echeverría's terms, this 'trans-naturalised' character of human behaviour gives rise to a 'communicative tension' between social individuals, whereby the production and consumption of use-values, or 'practical objects', necessarily also implies a production and consumption of significations, that is, semiotic communication. In section 3 we show how Echeverría elaborates this analysis by drawing on the work of Hjelmslev and Jakobson, conceptualising practical objects in terms of the 'biplanarity' of the sign (with its double strata of form and substance) and the social reproduction process in terms of the process of linguistic communication. This allows us to return to the question of language and to clarify its relation to the semiotic character of human activity in general. In section 4 we discuss the implications of a semiotic materialism for understanding capitalist societies. We explore Echeverría's idea of a 'totalising subcodification' which affects every act of material production and consumption, regulating and restricting human activity according to the exigencies of capital accumulation. This both offers an original account of the commodity as well as opening up a new perspective on the mechanisms of ideological domination and the possibilities of resistance to them.

\section{The language of real life}

Whilst the idea of 'languages' may unproblematically refer to systems of communication, the idea of language as such commands no single common definition within contemporary scientific discourse, where 'there exists no consensus about what specifically identifies "language in general"' (Ullrich, 2017, p. 180). The term is instead subject to a panoply of divergent and often incompatible definitions, a difficulty further confounded in relation to specifically human language and linguistic capacities. If the notion that linguistic communication (or, more emphatically, 'rational discourse', logos) as that which distinguishes the human from other animals may no longer be self-evident or theoretically palatable, and the apparent impossibility of identifying a unique function of human communication not found anywhere in the animal kingdom raises charges of 'anthropodenial' (De Waal, 1999) the appeal (and perhaps need) of defining human language in distinction from other forms of animal communication nonetheless endures. In minimal and residual form, this seemingly interminable endeavour is manifest in the tentative claim that 'human communication differs from animal communication not so much in specific traits but rather in its complexity and flexibility' (Naguib, 2006, p. 283). What might Marx's intellectual project - for which 'all mysteries which lead theory to mysticism find their rational solution in human practice and in the comprehension of this practice' (Marx, 1978) - offer in light of these aporias?

Marx, along with Engels, famously argues that whatever feature we might elect as the differentia specifica of humans, 'they themselves begin to distinguish themselves from animals as soon as they begin to produce their means of subsistence' rather than simply appropriating natural means of subsistence in the form in which they find them (1998, p. 37). Situating material production at the centre of 'real life', the Marxist account of anthropogenesis would seem to displace the centrality of 
language, relegating it to a secondary effect of 'sensuous human activity' and restricting communicative conditions to the possibilities circumscribed by the material conditions of that activity. The German Ideology offers much well-known textual evidence to support this reading. Most obviously, we can turn to the series of related formulations in the chapter on Feuerbach which trace the genesis of conceptual and discursive behaviors back to the practical context from which they emerge. 'Language is practical, actual consciousness', Marx and Engels argue, whilst consciousness, in turn, is determined by (material) life, not vice versa as idealist philosophy would have it. 'What individuals are', then, including how they think and communicate, 'depends on the material conditions of their production'. The cumulative effect of these statements is to present us with an unequivocal causal hierarchy: 'real life' first - that is, practice, material production - then language and consciousness, its 'direct efflux', after (Marx and Engels, 1998, 36-43). And this is certainly how many dominant currents of Marxism have, for the past one and a half centuries, received these polemical asseverations, most notably in the hardened dogma of a determining economic 'base' and a determined 'superstructure' that would encompass the full range of conceptual and discursive practices associated with language.

But what, then, are we to make of the elliptical and momentary appearance of 'the language of real life', which Marx and Engels identify with the fundamental foundation of actuality, 'the material intercourse and material activity of men’?:

The production of ideas, of conceptions, of consciousness, is at first directly interwoven with the material activity and the material intercourse of men - the language of real life (Marx and Engels, 1998, p. 42)

Does this not suggest an alternative reading departing from the recognition of an internal differentiation within the notion of language itself, between a general form isomorphic with 'real' activity, i.e., production, and a specific form bound to an 'imaginary', discursive domain generated by the former? As Wolfgang Fritz Haug notes, language is here redoubled, both as one of the 'original moments' of human life, and metonymically, as the entirety of that life, insofar as it 'occupies the key-position of what is supposed to substitute the hermeneutics of spirit' (Haug, 1996, p. 6).

Following Echeverría we wish to radicalise this insight, to push the correlation between communicative process and material production/consumption beyond its metonymic containment, to the point at which they fuse into a seemingly novel conceptual synthesis. More than simply insisting that Marx 'introduces the dimension of standpoint-related practical relevance into the understanding of judgement and predication' (Haug, 1996, p.9) or even that language is simultaneous with rather than secondary to 'real life' (Rehmann, 2013, p. 25), we wish to show that a 'communicative tension' suffuses and conditions each and every act of human practice, such that between the process of production/consumption of practical objects and the process of the production/consumption of significations there is an essential identity' (Echeverría, 2010, p. 85). Yet, as Echeverría demonstrates, this proposition is not so novel, nor does it require a 'violent reading' to be vindicated within the terms of Marx's thought. The identity of practice and signification, of production and communication, is implicitly present within Marx's conceptual apparatus, specifically his theory of the production and consumption of practical objects, the transhistorical basis of every human society. 
Furthermore, not only can the presence of this communicative dimension be uncovered at the foundational level of human practice in Marx's thought, its elaboration constitutes an essential moment of the comprehension of that practice, and therefore his entire theory of social production and reproduction.

\subsection{Practice as 'transnaturalised' action}

The recognition of a semiotic or communicative dimension to production and consumption emerges from a close examination of Marx's central concepts of practice, labour, production and reproduction. Each of these concepts refines the same basic notion of 'objective activity' through which humanity 'acts upon external nature and changes it' (Marx, 1978; 1976, p.284). Following the principle of anthropogenesis established in the German Ideology (the production of means of subsistence) Marx, in Capital, specifies a further distinguishing feature of this activity as an 'exclusively human characteristic'. The labour through which production occurs can be distinguished from all other animal behaviours insofar as its outcome is conceptualised in anticipation by the producer, before the activity that realises it is set in motion:

A spider conducts operations which resemble those of the weaver, and a bee would put many a human architect to shame by the construction of its honeycomb cells. But what distinguishes the worst architect from the best of bees is that the architect builds the cell in his imagination before he constructs it in wax. At the end of every labour process, a result emerges which had already been conceived by the worker at the beginning, hence already existed ideally. Man not only effects a change of form in the materials of nature; he also realizes [verwirklicht] his own purpose in those materials. And this is a purpose he is conscious of, it determines the mode of his activity with the rigidity of a law, and he must subordinate his will to it. (Marx, 1976, p. 284)

The worker's anticipatory conceptualisation of the product expresses the distinctive principle governing the human metabolism with nature, a principle absent from every non-human metabolic relation: the 'realisation' of purposes that, in their full scope and effects, are not determined by an instinctually given schema of behaviour encoded at the biological level. It is this under-determinacy of human practice at a 'natural' level which opens the conceptual space for Marx's analysis of varied and evolving historical forms of social production and self-realisation. For whilst labour is the everlasting nature-imposed condition of human existence $[\ldots]$ common to all forms of society in which human beings live' (Marx, 1976, p.290) its purposes and forms are not fixed but mobile: 'it must not be considered simply as the reproduction of the physical existence of the individuals. Rather it is a definite form of activity of these individuals, a definite form of expressing their life, a definite mode of life on their part' (Marx \& Engels, 1998, p. 37, emph. ours). Corresponding to any definite mode of life is a specific set of productive capacities and consumption needs, an 'ensemble of social relations' structuring the collective activities of mutually dependent individuals, and a delimited instrumental 
field' of natural and technical resources - these are the 'material conditions' of their production which form the background and context for this activity.

Marx's theory of production thus operates on the basis of a distinct relation between natural necessity (of physiological reproduction) and historical contingency (of the social and technical manner in which that necessity is obeyed), an idea echoed in Sartre's claim that praxis is an 'experience of both necessity and freedom' (Sartre, CDR v1, p. 79). The lack of a 'biologically sanctioned' (Marcuse, 1973) or generically distributed (Marx, 1978) image of human existence, along with the necessity of its concretion in historically definite forms, places the onus upon social individuals to determine the 'definite mode' in which they co-exist, both in terms of the relations structuring their activity, the material means through which that activity occurs, and the purposes or 'project' that this activity 'realises'. Humans do not only 'live' their nature passively, as if it were given and fixed, rather they must actively make (and remake) it for themselves. Precisely through this constructive activity do humans (both individually and as a collective) emerge as subjects:

'The ensemble of relations of interdependence between the members of the social subject requires a concrete figure that must be synthesized by the social subject itself. The sociality [...] of this subject exists as the matter with which it, as the totalization of social individuals, constructs its identity and the differential identity of its members. To be a subject, subjectness [sujetidad, consists thus in the capacity to constitute the concretion of sociality (Echeverría, 2014, p. 27)'

The capacity 'to take the sociality of human life as a substance to which it can give form' (Echeverría, 1998, pp. 77-8) is not only a potential, but is necessarily active in each and every moment of life, such that the 'mode' of that life is always 'in play', contested, penetrated by an instability and transience in various degrees of arrest or activation. As Marx affirms, 'society is no solid crystal, but an organism capable of change, and constantly engaged in a process of change' (Marx, 1976, p. 93). Recalling Aristotle's definition of the human as a Zoon Politikon, Echeverría designates this capacitynecessity as the 'basic politicity' characterising all human practice, and as that which gives rise to the 'meta-physical' dimension of human existence which 'structurally subordinates its physical stratum of functioning to its "political' stratum"” (2014, p. 36). Human behaviour is thus both 'transnaturalised', in that it transgresses solely bio-physical determinations, and 'transnaturalising', in that it negates given objective forms, reworks them and constructs new forms that transcend and thereby reinvent natural schemata. As an 'ontological' condition, the basic politicity of transnaturalised life is also that which founds the semiotic character of all acts of production and consumption. This is because of the uncertainty the lack of biological determination introduces into the coherence and correspondence between the two basic phases which constitute the reproductive process of human life: production and consumption.

2.2 Communicative tension and the practical object 
Marx argues that when viewed 'as a connected whole, and in the constant flux of its incessant renewal, every social process of production is at the same time a process of reproduction' (Marx, 1976, p. 711). The protean quality of human labour marks this entire process of reproduction in its cyclical unfolding, a process whose success depends upon the efficacy of the 'definite form' through which it is realised. Involved in any form of reproduction is the production of objects in one phase, which go on to be consumed in the next. But without a biologically determined schema of object formation and consumption to guarantee its harmonious functioning, this relay is marked by a fundamentally ambivalent character in which capacities and needs may not always complement each other. In a letter to Kugelmann, Marx pointed out that "Every child knows a nation which ceased to work, I will not say for a year, but even for a few weeks, would perish. Every child knows, too, that the masses of products corresponding to the different needs required different and quantitatively determined masses of the total labor of society. (1868)

Not only a shortage of productive activity, but a dysfunctional organisation of that activity can precipitate a catastrophic non-correspondence between production and consumption. Only if the form and quantity of produced objects are adequate to the needs of social consumption can reproduction proper take place. Between production and consumption, then, emerges a 'communicative tension', an ambiguous interplay of needs and capacities. This tension finds its resolution in the 'practical object', which emerges from production as result and enters into consumption as condition (be it 'productive' or 'unproductive' consumption) (Echeverría, 2010, p. 74). The 'practical object' is precisely what Marx refers to by the category of 'use-value', that is, a thing that 'satisfies human needs of whatever kind' (Marx, 1976, p. 125), mediating between the subject of production and the subject of consumption, and thus vindicating (or not) the effectivity of a particular mode of social production and reproduction, of a particular a mode of life.

It is in the mediation of these two phases by the practical object that the semiotic character of human activity is made manifest. As a produced good, something given material form in the process of production, a practical object is the 'bearer' of the producers' intention: the intention of satisfying a need for the subject that will consume it (Marx, 1993, pp. 300-1). This practical intention is what is conceptualised by the producer(s) in advance of their actual activity, guides the process of their labour, and becomes inscribed in the material form of the object:

Labour is not only consumed, but also at the same time fixed, converted from the form of activity into the form of the object; materialized; as a modification of the object, it modifies its own form and changes from activity to being (Marx, 1993, p, 300).

Through this process producers selectively concretize and thereby restrict the open and abstract possibilities of material life, for example satisfying the hunger of the consumer by the cultivation or preparation of specific comestibles in a specific manner, transforming the land, or developing certain tools and techniques in the process (Echeverría, 2014, p. 31). Yet because of the fluidity and impermanence of this 'transnaturalised' cycle, in which no instinctual schema guarantees the adequacy of produced goods to consumption needs, the practical intention carried by the object functions not merely as an unambiguous 'signal', but rather as a 'message' that is 'communicated' to the consumer, a message to be 'interpreted' practically in and through the act of consumption. The process of 
communication at stake here must, therefore, be understood as an open-ended process of practical signification.

Furthermore, in this communicative act, the socio-practical intention transmitted by the producer via the object does not only pertain to the satisfaction of a direct need, it also anticipates a subjectivising, formative effect upon the consumer (Marx, 1993, pp. 91-92). For Echeverría, following Marx, labour is 'an invention and the carrying out of a project; a project that is only immediately the construction of a thing, which indirectly but ultimately is the construction of the subject itself.' (Echeverría, 2014, p. 29). This is why what social individuals are coincides, in the final instance, 'with what they produce and with how they produce' (Marx \& Engels, 1998, p. 37). Practical objects, or use-values, in their immense diversity of forms, are therefore what secure the unity and coherence of a mode of life, in its reproduction over time (between production and consumption, between generations) and space (between individuals and societies). Simultaneously, a socially reproductive totality, in its definite form, establishes the global conditions of intelligibility and utility for every practical object and act which appears within it. A mode of life is always, then, a 'project of sense'.

\section{Semiotic Materialism}

Reading Marx in this way reveals human social life to be marked by a dual structure, generated by convergent teloi - physiological and 'political'. The 'political' telos guiding human existence acts upon the physiological telos of biological survival, subsuming it under a determinate social form through which it is to be realised, such that for the human, 'the reproduction of its animal materiality is the bearer of a reproduction that transcends it, that of its social materiality' (Echeverría, 2014, p. 27). The pre-eminence of this 'trans-naturalising', socio-historical dimension to practical life affirms the human capacity and necessity of giving form to its own material activity, to endow itself with a concrete identity, albeit as something that is always in question, perennially in the process of definition and redefinition. This dual structure splits apart the reproduction process which realises and sustains material life, fracturing it in the hiatus between the production of practical objects and their consumption. It is this hiatus, operative both temporally and intersubjectively, which establishes a 'communicative tension', a practical ambiguity and uncertainty from which the semiotic character of human life emerges.

Echeverría is able to deepen and radicalise the analysis of this semiotic character by critically integrating Marx's account of social reproduction with a number of theoretical elements derived from linguistic theory. ${ }^{2}$ Specifically, he proposes that

(1) the 'practical objects' through which human reproduction is realised are constituted by the same 'biplanar' structure which Louis Hjelmslev identifies within the sign.

\footnotetext{
${ }^{2}$ Whilst Hjelmslev and Jakobson's works are the principal resources, alongside Marx, for Echeverría's semiotic materialism, it should be noted that he also engages critically with other linguists (Saussure, Coșeriu, Martinet, Benveniste) and a range of philosophers and anthropologists (Sartre, Hegel, Heidegger, Lévi-Strauss, LeroiGourhan, Caillois) in order to develop his unique account of human social reproduction (See Echeverría, 2010; 2014).
} 
(2) Marx's account of the reproduction process in its totality is structurally homologous, and indeed 'essentially identical' with, Roman Jakobson's model of the process of linguistic communication.

The first of these elements enables Echeverría to specify the semiotic core of social life as expressed in the structural composition of the practical object, whilst the second establishes the global context of that semiosis and its basic constituent elements, or 'functions'. Taken together in their complementarity, Hjelmslev's theory of the sign and Jakobson's theory of communication form the basis for a semiotic materialism capable of grasping both the 'language of real life' - that is, human practice as such - and properly linguistic communication.

\subsection{The biplanarity of the practical object}

As Echeverría highlights, practical objects, or use-values, are, for Marx, the means by which the communicative tension between social individuals in the moments of production and consumption is resolved. Expressing the duality governing human behaviour, practical objects are constituted by two strata or levels of objectivity: the purely natural where 'the object would be the mediating entity of the purely animal reproduction of producers/consumers, of that functioning to which social reproduction would be reduced if it could cease to be what it is' and a second level 'where the first stratum is encountered as formed or refunctionalised', where 'the object is the entity that makes possible this physical or animal reproduction of the subject and social individuals, but in terms of the strictly "political" or subject-relating substrate of their reproduction' (Echeverría, 2014, p. 30).

By their appropriation and integration into a transformative process of labour through which they are 'formed or refunctionalised', physical materials are endowed with a practical intentionality directed toward a consumer-subject, and thus 'sublated', elevated from their merely 'natural' status, attaining a social objectivity. The practical object can thus be conceptualised as a piece of natural material inserted into the practico-communicative relation between the subject of production and the subject of consumption; it is a piece of signifying matter, or piece of nature in and through which a communicative act takes place (Echeverría, 2017, p. 110). There is no production, then, that is not at the same time signification, and there is no communication that is not at the same time an appropriation and formation of natural material: to execute any action, to produce anything, to provoke the least transformation in nature, always equals, in some manner, the composition and emission of a determinate signification in order that the other, in capturing it, be it in the slightest of perceptions, "decomposes" and consumes it, and would thus be able to change itself by virtue of it (Echeverría, 2010, p. 75).

The human social reproduction process thereby transcends what would be a 'naturally' communicative relation, transforming it into a properly semiotic process, that is to say, a process of the production/consumption of signs rather than just signals (Echeverría, 2010, p.75, 98). The practical 'message' carried by the object is not only a signal which affirms the reproduction of the other according to a pregiven, fixed instinctual schema - thereby remaining unambiguous in its affective content - but a sign which carries a transformative intention, that proposes a particular concrete identity 
for the other (and, ultimately, the entire community) in light of the possibility - however subtle or repressed - that this identity could be (and indeed may be) otherwise. It is this fluidity, and the arbitrariness of the object's practical content - its use-value - in relation to the natural material in which it is inscribed (the wood can take the form of a table just as much as it can a ceremonial figure) which grounds its sign-character and confers on the process of its production/consumption the status of a semiotic process.

This recognition of the structure of the practical object as characterised by a double stratum or 'biplanarity' (physical/political) is grounded in Hjelmslev's insight that 'all scientific analysis, of any given object [...] implies, by necessity, the distinction between two strata, or hierarchies, that we can identify as form and substance' (Hjemslev, 1971, p. 55). Radicalising Saussure's 'science of pure form', Hjelmslev argues that the openness of the relation between linguistic form and substance implies a liberation of form from the restricted schemas of substance such that it has 'no natural designation' and 'can therefore be designated arbitrarily in many different ways' (1961, p. 108, 105). This decoupling of the form and substance at the level of their functioning, such that neither exhausts or fully maps the other in terms of its processual unity and coherence, but always leaves an irreducible remainder, is what establishes the 'biplanar' character of all semiotic systems: 'the two planes, when they are tentatively set up, cannot be shown to have the same structure throughout, with a one-toone relation between the functives of the one plane and the functives of the other' (1961, p. 112).

Hjelmslev thus deepens Saussure's account of the biplanarity of the linguistic sign, showing that there are further elements that come into play in its constitution. Specifically, Hjelmslev proposes that along with the stratum of form - with its two planes: expression (signifier) and content (signified) - the sign also involves the second stratum of substance (substance of content and substance of expression). This substance is drawn from a semiotically 'amorphous' matter that Hjelmslev describes as a 'purport' and which serves as the base or substance of a form.

For Echeverría, this deepened account of the sign enables us to comprehend the structural composition of the practical object. The internal 'non-conformality' of the planes of substance and expression is precisely what is expressed in the dual dimensions of the practical object (and, more broadly, of the reproduction process of human life to which it is bound) as at once both natural and socio-historical, and, moreover, as trans-naturalised: constituted by a hierarchical biplanar structure whereby the sociohistorical plane recodes and subsumes the 'natural' plane of functioning. The stratum of form, in this context, would refer to the first of these planes, practicality or the 'social objectivity' of the object as a use value, as a thing capable of satisfying some need by virtue of its physical organisation. The stratum of substance would be the plane of the 'natural' material, which is endowed with and bears this form:

The originary project of symbolization consists precisely in a transcendence of the spontaneous articulation that the behavioural disposition of the animal, as the deep stratum of the behavioural disposition of the human, establishes between the natural phenomena external to its organic life and their presence in so far as they are functionalized for the reproduction of its principle of living organicity. The process of animal life delivers to the 
process of human life a 'protoform' from nature; human existence converts this into the substance of the socio-natural form (Echeverría, 2014, p. 34).

The 'protosignifying' or 'protoformal' quality of that which is given as substance at a 'natural' or 'animal' level of functioning is crucial here for grasping the process of symbolisation and the presence of meaning materialistically, that is, as historical, rather than originating in a suprahuman source of 'revelation' (Echeverría, 2010, p.96). The process of practical semiosis is never a 'pure' transmission of practical intentionality between subjects: "spirit" is from the outset afflicted with the curse of being "burdened" with "matter" (Marx \& Engels, 1998, p. 49, trans. modified). Furthermore, this matter, which functions as the unavoidable medium of semiotic communication - the raw material, or 'contact' material between communicant and interpretant - is not a mute and neutral vehicle for subjective intentions, but introduces its own suggestive or distorting determinations. In the appropriation of natural material and its subsumption under a socio-practical form, a third source of 'meaning' is thus revealed alongside the emitter and receiver: that already found in the natural material in which the 'message' is transmitted, in the spontaneous state in which it is encountered prior to its formation (Echeverría, 2014, p. 32). This is the 'proto-signifying' character of that which comes to occupy the place of substance within the biplanar structure of the sign. It demonstrates the temporality or historicity - rather than transcendent origin - of every signifying form, the situatedness of all meaning within an unbroken chain of metabolic interchanges, such that 'every form implies in some manner an "imbrication" upon a previous form' (Echeverría , 2010, p. 93). Rather than emerging ex nibilo, then, the practical object's signifying content is always present as both 'the result of a preceding "symbolization" (or a proto-symbolization)' and 'the support or substrate of a new "symbolizing effect"” (Echeverría, 2010, p. 93).

The semiosis of human life thus occurs on a practical level, embedded in the production and reproduction of material objects, which always occurs according to and expresses a definite form of life, within the historical continuum of such forms. We find in Marx's account of the dual structure of labour and its object - dual even analytically prior to its capitalist form in what he terms its 'natural' form - the basic elements of an account of practical signification, which constitute precisely what should be understood as the grammar of the 'language of real life'. For Echeverría, human practice, in which every subject-object relation is configured, is a process of constitution of meaning in the real, establishes a basic semiotic relation on the basis of the biplanar 'non-conformality' of the natural and socio-historical levels of human existence. (Echeverría, 2017, p. 43-44). The conditions of practical signification, however, must be explored not only in relation to this biplanar object, but with relation to the total context of meaning within which any communicative act, and therefore also of the 'message' or practical intention, derives its conditions of sense. That is, the social reproduction process in general.

\subsection{Social reproduction and linguistic process}

The production and consumption of practical objects obtains an 'essential identity' with the production and consumption of significations. More specifically, for Echeverría, 'to produce is to 
communicate, to propose to another a use-value in nature; to consume is to interpret, to validate that use-value found by another. To appropriate nature is to convert it into significance' (Echeverría, 2014, p. 32). The 'practical nature' and 'signifying character' of the practical object are, in this manner, 'one and the same thing', so that 'significance is nothing more than the quintessence of the practicality of the object' (Echeverría, 2010, p. 100). Crucially, however, the practical significance that a use-value bears is not simply imprinted into its physical 'body', it is constituted in a relation between the discrete physical entity and the total social context within which it is produced and consumed. The relational (rather than simply physical) objectivity of practical objects is evident as much in the social power of money as it is in the emotive power of poetry. Comprehending the mode in which this relationality is constituted demands an analysis not only of the practical object in its biplanar structure, but also the entire communicative cycle in which this structure is effective.

Echeverría draws attention to a 'homology' between Marx's analysis of human practice - grasped in its entirety as a process of social reproduction - and Jakobson's diagrammatic model of the act of linguistic communication, with its 'factors' and corresponding 'functions'. ${ }^{3}$ On the basis of this homology the two models afford their integration into a single practico-communicative unity, such that the process of linguistic communication and the process of production/consumption would simply describe the same real process from two distinct analytical perspectives (fig. 1.). Conceptualised as a unity, in the process of productioncommunication the producer-addresser, can be said to cipher-produce a use-value-message, or a signifying practical object, with a transformative intentionality directed toward a consumer-addressee who interprets-deciphers it, accepting thus (to whatever extent and in whatever manner) the transformative intention that the use-valuemessage brings with it. As we have seen, this signifying practical object is created by way of an appropriative transformation of nature that 'forms' the use-value or referent, an act realised by a producer-addresser who transforms the raw material-contact of a protosignificative-natural material, making use of a concrete code inherent in the instrumental field to impress a project of meaning upon the object (Echeverría, 2010; 2014, pp. 32-33).

\footnotetext{
${ }^{3}$ In Jakobson's terms the process of communication is composed of six 'factors': addresser, message, addressee, context, contact and code. These factors come into play with six 'functions': emotive, poetic, phatic, conative, referential and metalingual (Jakobson, 1960).
} 

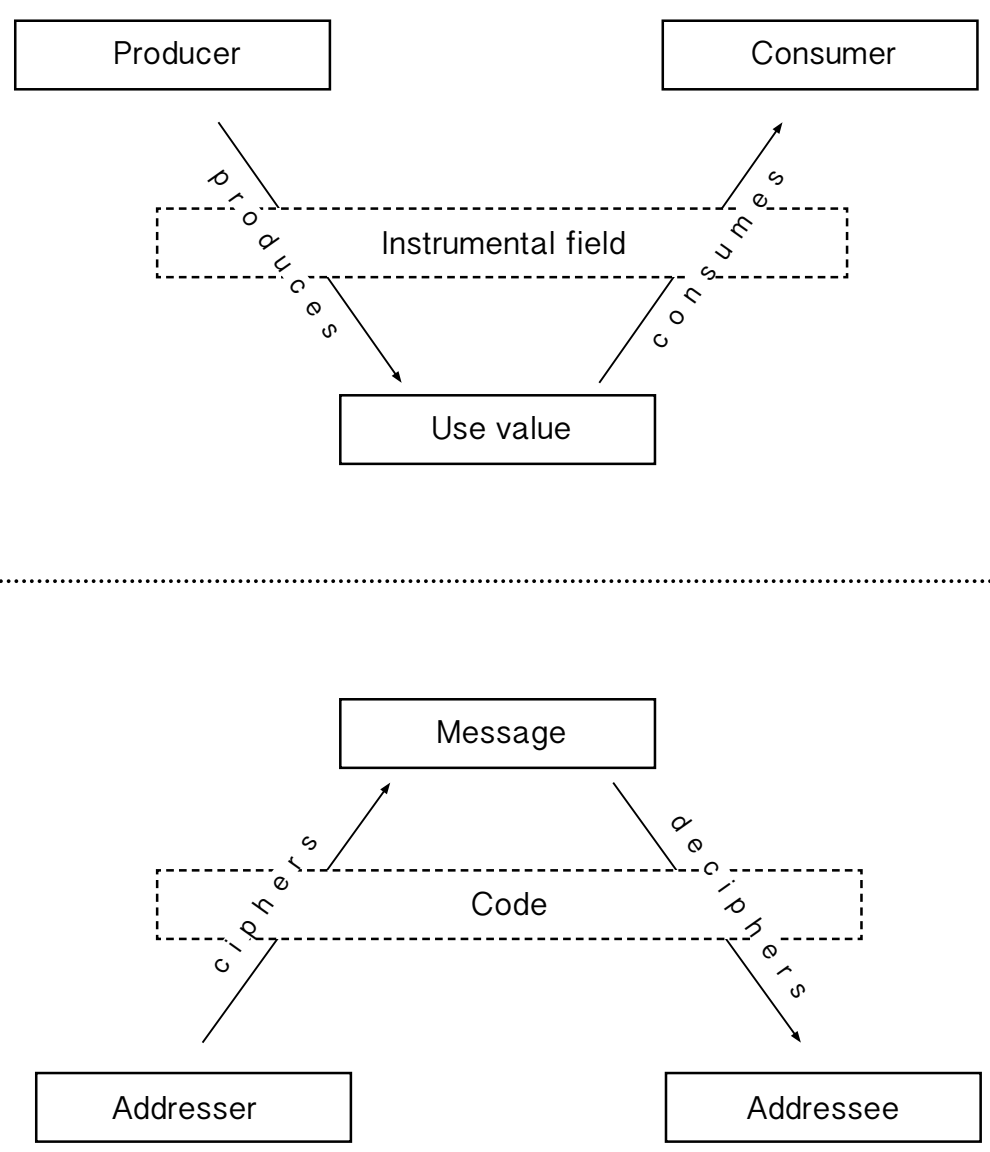

Fig. 1. The homology between communication and production/consumption ${ }^{4}$

Whilst Jakobson recognises the referential or cognitive function - the appropriative transformation of nature in Marx's analysis - as the predominant function of linguistic communication (Echeverría, 2010, p.121) this does not reduce semiosis to a transmission of information about a referent. Rather, in the human process of linguistic communication, any linguistic act synthesizes a complex articulation of interpretative communicative functions: 'we could [...] hardly find verbal messages that would fulfil only one function. The diversity lies not in a monopoly of some one of these several functions but in a different hierarchical order of functions' (Jakobson, 1960, p. 353).

In the context of the social reproduction process, two other functions take primacy in relation to the 'transnaturalised' quality of human activity: the metalingual (or, for Echeverría, 'metasemic') function related to the 'code', and the poetic or aesthetic function related to the 'message'. The metalingual/metasemic function is that function of linguistic activity which takes the code in its totality as a directly transformable object rather than as a given and immutable structure; it is that function by which the 'rules of the game', or the norms according to which the referent acquires meaning, are altered. The poetic/aesthetic function, on the other hand, is that function of linguistic activity which makes reference to the open and multiply realisable possibilities that an emitter has of using the code to transform the contact and thereby construct a specific message. In other words, the 
poetic/aesthetic function identifies the process through which contact between people becomes signifying, exceeding a univocal relay of signals, in the selective determination of linguistic forms (i.e. signs). The metalingual and poetic/aesthetic functions thus correspond, in turn, to the capacity to manipulate general and specific signification. Both are key to understanding the semiotic specificity of human communication, and, in a broader sense, to understanding the human capacity to give practical form to material objects according to a properly 'political' telos: the general structure of mediation by which a human community gives form to and thus realises itself in and through a concrete mode of life.

The metalingual and poetic functions underpin the singularity of the human practicocommunicative code, which comes to displace and subsume bio-physical determination as the principle governing the social and practical behaviour of individuals. It is this code, in any one of its concrete configurations, which shapes and guides the 'political' telos guiding all praxis prior to its actualisation. For Jakobson, the communicative code is something 'fully, or at least partially, common to the addresser and addressee (or in other words, to the encoder and decoder of the message' (1960, p.353), thus acting as a shared framework of communality between individuals and enabling the symbolic ciphering and deciphering of information upon a contact material. From a Marxist materialist perspective, Echeverría argues that this 'fundamental symbolizing entity' - the code, language (langue) in Saussurean terms - is embedded in the instrumental field available to the social subject to produce/consume the set of practical objects by means of which it reproduces itself: 'The most developed form of the social object is without doubt that of the instrument,' whilst 'the ensemble of instruments constitutes a complex totality, temporally and spatially organized: it is the instrumental field of society' (Echeverría, 2014, p. 31). This totalised instrumental field contains in potentia, and thus establishes as a defined horizon, all the possibilities of giving and receiving form that the subject can utilise to imagine and compose/decompose the object (Echeverría, 2010, p.112). The human social reproduction process, as the cyclical movement between production/consumption, or between the ciphering/deciphering of practical intentions, has this code as its condition of possibility, insofar as it is a process of communication/interpretation (Echeverría, 2014, p.33).

Moreover, because this 'fundamental symbolizing entity' is 'trans-naturalised', decoupled from the rhythm of evolutionary development spanning hundreds of millennia and instead bound to the social temporality of human history, the code is not closed but rather 'open source', transformable in a punctual and deliberate process. As such, practio-communicative agents, emitters and receivers of reflexive 'messages', possess the capacity to 'recode' the very means by which they materially act and co-exist:

The human uses a different code to all those that govern the behaviour of purely natural living beings; a code which, in being employed in order to constitute the sense of things, must likewise be, simultaneously, re-constituted, reaffirmed with either the same or another constitution. The process of production/consumption as a process of communication/interpretation is thus a process not only of signification but also, equally, of metasignification. (Echeverría, 2014, p.34) 
Expressed in linguistic terms, the metalingual function reveals the 'essence' of the code as something always subject to modification, and as such historical. In every instance in which the code is used, 'its project of sense is put in play and can enter into danger of ceasing to be what it is. The project of sense, which is the instauration of a horizon of possible significations, can be transcended by another project and comes to constitute the substantial stratum of a new instauration of semic possibilities' (Echeverría, 2014, p. 35). The series of transformations and reconfigurations through which the code passes constitutes its real history, which 'takes place as a succession of imbrications between projects of sense, resulting from the refunctionalization $[\ldots]$ of preceding projects by new sense-giving impulses' (Echeverría, 2014 p.35). The code underlying all practical semiosis - what Marx referred to as a 'mode of production' - is thus the most important and determining element present in the process of social reproduction and must be comprehended in its concrete historical specificity if a critical engagement with the transformative potentials and constraints of social reality is to be achieved.

\section{3. practical semiosis and linguistic communication}

What, then, becomes of the properly 'linguistic' level of human communication, in light of the semiotic materialism elaborated above? Following Hjelmslev's assertion that 'a language (in the ordinary sense) may be viewed as a special case of this more general object' (1961, p. 107) i.e. a semiotic system, or for us a practico-semiotic system, we can now approach properly linguistic communication through Marx's materialist framework. If every practical object, formed by the transformative appropriation of a natural substance, is also something signifying, then a spoken linguistic message would present nothing more than a 'special case' of this, being distinguished only by the specificity of its 'sonic materiality':

Is not the pronunciation of a word a "labour" of transforming the acoustic state of the atmosphere, by means of certain "utensils" of the human body, which is "consumed" or enjoyed by being perceived auditorily? Is not the extraction of information out of or departing from the referent on the part of the emitter also, definitively, an "appropriation of nature" as that which takes place in any labour process, only here as an appropriation of the cognitive type? Is not the contact a "raw material" and the code an "instrumental field"? Is not the expression of the emitter a "project" and the appeal to the receiver an appeal to "transform" it? (Echeverría, 2010, pp. 85-86)

But not only is human language quite specifically an expression - no less material - of the general 'language of real life', it also acquires, for Echeverría, a privileged status within the 'transnaturalised' lifeworld. The semiotic singularity of the human condition, where the physical telos of life is appropriated as the support of a non-conformal 'political' telos, is manifest as much in its general structure as in 'the presence of an entire dimension of productive/consumptive existence that cannot be found in the natural universe, a properly semiotic reproductive dimension $[. .$.$] exclusive to the total$ [human] universe: language or independent semiotic process' (Echeverría, 2014, p. 32). As the 'autonomous existence' of its semiotic dimension, Language is the exemplary 'transnaturalising' moment of human life. Put simply, there is nothing more 'political' - in the sense of the capacity of 
a subject to give form - than language, where 'semiosis reaches the maximum of its effectiveness in the semiosis of the production/consumption of the "word" object' (Echeverría, 2010, p. 106). The word-object possesses an 'especially dense' semioticity that is inversely proportional to its direct practicality for the realisation of human 'natural' reproduction. It thus transgresses, to the furthest extent of all practical objects, the natural limitations of human behaviour, combining 'a minimum of practicality with a maximum of semioticity' (Echeverría, 2014, 35).

In language the self-realising and self-creating capacity of social individuals therefore finds its most refined 'instrument', operable "in a void" ignoring the direct, physical and social limitations, to which it would have to submit if it only 'spoke with facts' (Echeverría, 2014, p. 36). Because what it takes as its 'substance' is the most plastic of materials - the acoustic atmosphere or minimal visual marks 'the repertoire of forms/significations that can be articulated with its matter is infinitely greater than the ones that can be achieved with any other type of object' (Echeverría, 2014, p. 35). Language must thus be recognised as 'a special, 'purified' process of production/consumption of significations' that offers 'the privileged path for communication/interpretation' (Echeverría, 2014, p. 35).

What remains to be resolved within Marxist discourse is how this 'privileged path' of communication is to be related back to the 'language of real life' as such, and how this relation occurs under capitalist conditions. Marx himself identified and problematised this with reference to the question of ideology, but, treated more generally, the specificity of linguistic communication is of central importance for the critical comprehension of historical societies and their transformation, because:

'language not only passively condenses and refines the semiotic realizations of practice; on the contrary, it penetrates and interferes in each and every one of them with its own perspective. It not only serves, but also dominates them' (Echeverría, 2014, p. 36).

Recognising the co-determination of the two levels of semiosis in this way avoids the dual ideological matrices criticised by Marx as early as his theses 'On Feuerbach': the 'economistic' reduction of social reality to its basic material processes (the position associated with 'traditional' materialism) or the reduction of social reality to a unilateral creation of a thinking and speaking subject (the position associated with idealism). Yet this codetermination can only be grasped in its capitalist form by attending to the specific - and distinctive - configuration of the general practico-communicative code found within capitalist societies.

\section{4. semiotic materialism and capitalism}

The preceding analysis of the ontology and semiotics of human reproduction in its general, 'socionatural form' now enables us to explore the consequences of producing practical objects with use-values, or social wealth, as capitalist commodities, that is to say, as units of value in the process of capital's self-expansion (Marx, 1976).

As we have seen, in his analysis of the sign Hjelmslev reformulates and develops the description of the structure of signifying matter made by Saussure, or that which would be the 'message' in Jakobson's schema. In Echeverría's words, he discovers 'that the movement which 
constitutes the biplanarity of the sign depends on another, that which constitutes its double stratum of substance and form'5 (Echeverría, 2014, p. 38). This discovery is appropriated critically by Echeverría in order to deepen Marx's account of social reproduction and the transhistorical structure of use-values, or 'practical objects'. The biplanar structure of social reproduction is expressed in the biplanarity of the object as something both natural and social (that is, practico-signficative). But not only is the exposition of this transhistorical, transnaturalised structure enabled by utilising the biplanar schema, these elements also make possible the critical comprehension of what we could call the fetishistic process of signification, emergent from the characteristics of the practical object when it is produced as a capitalist commodity.

Jakobson's work, on the other hand, serves to trace the identity between production as realization and communication as semiosis, thereby establishing the immanently semiotic character of all human realization. Jakobson's conceptualisation of code, when correlated with the concept of an 'instrumental field', allows Echeverría to account for how the non-discursive 'language of real life' in capitalist societies, its practical semiosis - that is to say, the language that subjects or agents 'speak' in the mediated process of production/consumption of their social existence, of the practical objects and the social relations through which they reproduce themselves - is 'subcodified' by the abstract valorisation of value (giving rise to a dynamic of generalised commodification). It also enables an understanding of how properly linguistic communication is subjected to a 'totalizing subcodification', even in its theoretical discourse; a subcodification that establishes ideological constraints within the discursive field by impressing upon every possible message an affirmative and apologetic 'sense' in relation to the capitalist configuration of social life.

The impulse of capitalist economic rationality fundamentally modifies the socio-natural structure of human reproduction, and as such brings about a transformation in the communicative, semiotic dimension of human life by way of a 'subcodification of the code and the general tendency of the production/consumption of significations' (Echeverría, 2017, p.66). For Echeverría, this subcodification imposes a singular, diffuse and omnipresent message which is 'converted into the inherent and unquestionable principle of a systematic restriction of the entire set of possibilities that the general code delimits for the production/consumption of significations' (Echeverría, 2017, p.66). This subcode, he argues, inscribes the entire process of production/consumption with an apologetic sense in relation to the specifically capitalist or bourgeois configuration of social reproduction. The 'message' of this subcode, that subsumes the entire social process, is nothing other than the affirmation of a pseudo-natural identity between the reproduction of a communitarian subject and the expanded reproduction of capital. What is repressed in this identification is the non-conformality of the physical and the (capitalistic) social levels of functioning. They are ideologically compressed into a 'monoplanar' system, such that the capacity to alter and reconfigure the capitalist 'mode of life', to replace it with another mode, is occluded, appearing to social individuals as unnatural and therefore impossible.

${ }^{5}$ For Echeverría, the relation between the substance and form of the sign described by Hjelmslev offers the necessary conceptual basis for the relation that Jakobson intends to establish between message and contact (Echeverría, 2010, p.95) 
The subcodification of human practice by capital endows the practico-significative object with a double social dimension; systematically produced as commodity, it becomes an object with a fetishistic signification or meaning superimposed upon it, that which Marx designated as the commodity's 'spectral' or 'phantomlike objectivity' (1976, p. 126), in addition to and regardless of its 'practical content',. As Marx outlines, the capitalist production process is the contradictory unity between the labour process and the valorization process (1976). This double determination of production, itself grounded in the double determination of labour as abstract/concrete, gives to the commodity a redoubled social character (value/use-value). These double strata are expressed also in the semiotic dimension of life, in the production process of meaning and signification. The basic signifying structure characterising the practical object, generated by the formation of natural material according to a practical intention, is 'overcoded' in the commodity, and is itself converted into a substance, the mere material 'bearer' of a value-form. In the commodity we are dealing with a unique, complex structure of biplanarity, uniting the socio-natural stratum of use-value and the sociocapitalist stratum of value. The latter stratum subsumes the former, acting as a 'superimposed and parasitic form' (Echeverría 2017, p. 67) through which it is configured in a capitalist mode; this is why, through its commodification, the presence of a basic sense within the practical object is obscured, distorted and inaccessible, as in a hieroglyph. Marx's analysis of the commodity thus shows the process of communication (both practical and properly linguistic) in capitalist societies to presuppose the presence, alongside the concrete agents that produce and consume their own significations and projects of sense, of another signifying agent: value in the process of valorising itself, capital operating as the 'automatic subject' of the social process (Marx, 1976, p. 255). 'It is as if there was someone or something that enters into action along with the movement of our own hands, distorting the form of what we do; someone or something talking with our own breath, twisting the meaning of what we say' (Echeverría, 2007, p.10).

There is not a single practical object that is neutral (functional in the abstract, without orientation toward a specific project of life or sense) or that remains outside of the determination of material life by a specific form of reproduction. Under capitalist conditions, the universalised imposition of the value-form upon every practical form (which thus effectively becomes a substance for capital) enforces its orientation towards the project of accumulation. The code itself, language and the instrumental field, are already ciphered with a capitalist form. Accordingly, we cannot lose sight of the fact that the 'language of real life', when subcodified in a capitalist way, configures language as it does any other practical object, converting it into a properly capitalist object. Focusing the general analysis of subcodification upon the terrain of theoretical discourse, Echeverría argues that there is a central, simple and radical signification inscribed in the linguistic code which produces a totalizing subcodification capable of re-forming every possible explicit message, becoming thus the latent kernel of every theoretical message. The basic semiotic relation which constitutes the grammar of real life within modernity regulates and delimits the capacity to provide a theoretical account of the object, of reality, in this manner (Echeverría 2017, p. 38).

Grounding the production of linguistic significations in this account of a generalised subcodification by capital has important implications for how we conceptualise the possibility of 
constructing an effective critical discourse, that is, a struggle on the specifically discursive terrain. Given the apologetic sense which linguistic entities, like any other practical object, bear a priori towards the capitalist reality within which they exist, then any 'common-sense' validity, any spontaneous and self-evident 'truth', strengthens and supports those 'messages' which affirm that reality. This is why, as Marx and Engels state, 'for the bourgeois it is all the easier to prove on the basis of his language the identity of commercial and individual, or even universal, human relations, as this language itself is a product of the bourgeoisie, and therefore both in actuality and in language the relations of buying and selling have been made the basis of all others' (1998, p. 248, emph. ours). Correspondingly, those messages which would serve to criticise and oppose the established capitalist order, that would be deployed as the basis of an anti-capitalist discourse, are debilitated, or even inverted:

A confrontation of such a nature will subjugate it to the rules of the game of bourgeois discourse and will make of it, in the last instance -and unwillingly-, a discourse apologetic of the capitalist order (Echeverría, 2017, p. 132).

In this situation, where the effective construction of an alternative positive discourse on social reality is attenuated by an extra-discursive subcodification, critique becomes the only adequate theoretical mode of contesting the capitalist mode of life. This is why Marx, rather than outlining a 'proletarian science' to be wielded in opposition to capitalist ideology, works immanently within bourgeois social discourse in its most sophisticated (in both senses of the term) form: political economy. In Capital, Marx makes the 'petrified relations' of capitalist society 'dance by singing their own tune to them' (Marx, 1992, p. 247); by demonstrating, by departing from their own presuppositions, their alienating and exploitative character.

\section{Concluding remarks}

The 'transnaturalised' character of human social life is the foundation of the semiotic materialism we outline here. Although many discrete examples can be found of learned, transmitted and apparently 'spontaneous' behaviours by which non-human animals transgress their instinctual codes, this always occurs in a limited manner. Human life, by contrast, is, for Marx, inherently characterised by this transgression; it is the differentia specifica of human existence to find and select its own form, to constantly put this into play and reinvent its concrete identity. The predominance of this 'political' telos over any 'natural' schema, and the instability of any given mode of life it implies, gives rise to a communicative tension throughout the entire human reproduction process which opens the possibility for a semiotic analysis of the 'language of real life'. As Echeverría's distinctive reading of Marx highlights, human communication occurs not only with language in the specific sense, but also through the production and consumption of practical objects, through the form of those objects, which relays practical intentions between social individuals. In this way human practices can be grasped as signifying, and the objects through which human reproduction is realised can be treated as signs; they express, in the biplanar configuration of a natural substance and a social form, both the mode of life which conditions their emergence and the political impulse, however subtly manifest, to sustain or alter that mode. 
This strong integration of semiotic and materialist perspectives offers powerful conceptual resources for engaging with questions around social life, both in general and in its concrete historical forms, as well as linguistic communication, theoretical conflicts and ideology. It offers a fresh approach to Marx's work, in particular his accounts of practice, commodification, the subsumption of labour, ideological domination and fetishism. But foregrounding the semiotic character of human social does not simply serve to identify a static truth, it has two specific functions tied to the practical, transformative horizon of Marx's theoretical project. Firstly, to elaborate and clarify the uniquely political dimension of human life in its general structure, the capacity to form and reform the activity, the material environment and, thereby, the identity of a social group, in a manner which places the possibility of different and more amenable conditions at the centre of critical social enquiry. This is of particular importance with relation to language, where the malleable and unstable form of social life as such, its inherent 'politicity', finds its purest and most emphatic expression. Secondly, to identify with precision the mechanisms of control by which capitalist social relations regulate and restrict the possible realisations of this capacity to give form, shaping the production of significations on both on a 'material' and 'discursive' level. The idea of capitalist 'subcodification' is crucial in this respect, insofar as it deepens Marx's account of the manner in which the entire practicocommunicative code, the instrumental field enabling social production, is determined by an abstract and parasitic logic which obscures its own peculiarity. Generalised commodification and the organisation of production toward accumulation imprints itself within the structure of every practical object regardless of its material particularity, endowing it, as a signifying object, with an affirmative sense regardless of its particular message: that of the unbreakable identity between human relations and capitalist relations. This distorting and occlusive effect establishes the constraining theoretical conditions against which a counter-discourse critical of the capitalistic mode of social life would have to be constructed, suggesting that such a discourse cannot proceed positively, but only critically.

\section{Bibliography:}

Echeverría, B. 1997. Valor de Uso y Utopía, México City: Siglo XXI.

Crítico.

2007. Discurso de recepción del Premio Libertador Simón Bolívar al pensamiento

Caracas, 24 July 2007. Available online at:

http://www.bolivare.unam.mx/miscelanea/Discurso\%20Caracas \%20Julio\%202007.pdf [accessed

December 2017]

2010. Definición de la cultura. Mexico City: Itaca.

2014. 'Use-value: Ontology and Semiotics’ [1998], translated by Andrés Sáenz De Sicilia and Sandro Brito Rojas, Radical Philosophy 188, November/December 2014, pp. 24-38.

2017, El discurso crítico de Marx, Mexico City: FCE-Itaca.

Haug, W. F. 1996. 'The Language Question in Marxism Brecht, Gramsci and Wittgenstein', conference paper, available online at:

http://www.wolfgangfritzhaug.inkrit.de/documents/LanguageQuestioninMarxism.pdf [accessed December 2017] 
Hjemslev, L. 1961. Prolegomena to a Theory of Language, University of Wisconsin Press, Madison.

1971.

1971. 'La stratification du langage' [1954], in, Essais linguistiques, Éditions de Minuit, Paris,

Jakobson, R. 1960. Closing Statement: Linguistics and Poetics', in Style in Language, Cambridge MA, MIT Press.

Marcuse, H. 1973, On the Philosophical Foundation of the Concept of Labor in Economics, Telos, Summer 1973, no. 16, pp. 9-37.

Marx, K., 1868. Letter to Kugelmann, 11 July 1868, available online at: https://www.marxists.org/archive/marx/works/1868/letters/68 07 11-abs.htm [accessed Dec 2017].

1976. Capital: a Critique of Political Economy, Vol. 1: the Process of Production of Capital [1867], translated by Ben Fowkes, London and New York: Penguin.

1978. Thesen über Feuerbach. In Karl Marx and Friedrich Engels, Marx Engels Werke. Band 3. Berlin: Dietz Verlag.

1992. Early Writings [1843-44], translated by Rodney Livingstone and Gregor Benton, London and New York: Penguin.

1993. Grundrisse: Foundations of the Critique of Political Economy (Rough Draft). London: Penguin.

Marx, K. and Engels, F. 1998. The German Ideology [1845-6], translated by S.W. Ryazanskaya, New York: Prometheus Books.

Naguib, M. 2006. 'Animal Communication: Overview', in Encyclopedia of Language and Linguistics (2nd Edition), ed. Brown, K., Elsevier.

Rehmann, J. 2013. Theories of Ideology: The Powers of Alienation and Subjection, Leiden-Boston, Historical Materialism.

Saenz De Sicilia, A. Forthcoming 2018. 'Bolívar Echeverría', in Handbook of Frankfurt School Critical Theory, Vol. 1: Key Texts and Contributions to a Critical Theory of Society, Eds. Best, B., Bonefeld, W., O'Kane, C. and Larsen, N. London: Sage.

Saenz De Sicilia, A and Brito Rojas, S. 2014. 'Introduction to Bolívar Echeverría' (with Sandro Brito Rojas), Radical Philosophy 188, Nov/Dec 2014, pp. 20-23.

Sartre, J.P. 2004. Critique of Dialectical Reason, Volume 1: Theory of Practical Ensembles [1960], translated by Alan Sheridan-Smith, London and New York: Verso.

Ullrich R. 2017. 'From 'speech' to 'gesture': The 'oral' as norm in 'language' research'. In Interdisziplinäre Anthropologie, eds. Hartung, G. and Herrgen, M. Wiesbaden: Springer VS, pp. 179-207. 